\title{
Ensaio sobre a relação dos Zoomers com o consumismo moderno, seus impactos ambientais e a percepção do sustentável a partir do DIY
}

Nicole Curtinovi Martins;

Letícia Cabral da Silveira Sanches

resumo:

A geração $Z$ emerge em uma sociedade já caracterizada pelo modelo supérfluo de consumo e que colhe os frutos desse modelo através de uma crise ambiental generalizada. Contudo, mais atentos a esses fatores, tanto no âmbito de consumo quanto no de sustentabilidade ambiental, essa geração abraça novas formas de viver nessa sociedade. Marcados pela ascensão da internet, os chamados "nativos digitais", são uma geração que preza pela individualidade e pelo respeito, características que recaem sobre seus hábitos de consumo. Eles trazem novos pontos de vista perante diversos vieses sociais e, assim como os outros jovens em suas épocas, buscam por melhorias nessa sistemática. Neste artigo, as consequências dessas características serão qualitativamente analisadas através de uma pesquisa documental sobre a história dos hábitos de consumo da sociedade moderna e do movimento DIY, que vêm ganhando cada vez mais espaço dentro dessa sociedade.

palavras-chave:

DIY; consumismo moderno; geração Z; ressignificação 


\section{Introdução}

Neste artigo, foi elaborada uma pesquisa qualitativa através de análise documental com o objetivo de estudar a expressão de consumo da sociedade moderna, suas relações com a crise da sustentabilidade, observar as mudanças comportamentais de consumo no período da pandemia de Covid-19 e como essas mudanças podem ser consideradas como características da geração Z. As análises e interpretações sobre o consumo seguem o ponto de vista de Bauman $(2003 ; 2008 ; 2010)$; a história do design foi embasada a partir do trabalho de Magini e Belusso (2018); os impactos ambientais descritos a partir do Relatório de Brundtland (ONU, 2020) - complementado a partir do ponto de vista de um designer por Naime et al. (2012); os autores Francis e Hoefel (2018) e Owen, Napoli e Shin (2018) para comportamento da geração Z; ao passo que o movimento Do It Yourself foi embasado a partir das análises de Prado, Kuznetsov e Paulos (2010) e Rosa (2018).

Para Bauman (2010), os modelos de consumo iniciados a partir da revolução industrial e mantidos através de uma complexa sistemática que relaciona esses padrões com o modelo capitalista do século XXI, são um dos principais fatores para que comportamentos insustentáveis sejam mantidos e uma das principais razões para o crescimento exponencial da poluição neste século. Impulsionada por inúmeros fatores sociais humanos, como a produção em alta escala, o descarte irregular e a queima de combustíveis, essa poluição gera impactos ambientais, causando danos para o equilíbrio de todo o ecossistema terrestre (THE RISE..., 2015), danos que atuam em diferentes mecanismos sociais, permeando ações diárias e refletindo em acontecimentos que afetam todos organismos vivos do planeta, incluindo seu próprio causador: o ser humano. Para além da sustentabilidade ambiental, o consumo da "sociedade líquida" tem prejuízo social e econômico, colocando diversas populações sob exclusão e contribuindo para a manutenção da desigualdade social (BAUMAN, 2010).

Algumas iniciativas populares vêm buscando frear esse mecanismo ao longo da história e vem ganhando mais força com a ascensão da geração Z, que nasce entre 1995 e 2010 e cresce já inserida a uma realidade com forte presença virtual (FRANCIS e HOEFEL, 2018). Acostumados a fluida concepção de informações, esses jovens se caracterizam por buscarem sua própria individualidade, respeitarem a individualidade alheia e buscarem novas formas de performar o mundo que vivem (OWEN, NAPOLI e SHIN, 2018). Iniciativas como a do movimento DIY proporcionam a esse jovem a expressão de sua personalidade única e também os ajudam a satisfazerem as novas visões sobre o consumo, mais sustentável e ético. Com o isolamento social propiciado pela pandemia de COVID-19, esse tipo de movimento ganhou ainda mais adeptos (MAGUIRE, 2020) e pode trazer novas informações sobre o quanto as formas atuais de consumo são prejudiciais. É o caso do "dia de sobrecarga da Terra" - data em que os recursos renováveis disponíveis para o ano serão esgotados realizado anualmente. Em 2020, a data em que os recursos renováveis atingirão o limite anual foi marcada para 22 de agosto, 24 dias mais tarde que em 2019 (TRIBUNA, 2020). É o maior intervalo de tempo catalogado nos últimos 15 anos e, segundo o estudo, as mudanças nos hábitos de consumo durante a pandemia de COVID-19 são o ponto principal para esse adiamento.

Os capítulos a seguir buscam compreender mais profundamente essa sistemática e quais foram as características que contribuíram, ao longo das últimas décadas, com a manutenção desse sistema. Dessa forma, ao final do artigo, será possível propor uma reflexão sobre os rumos para os quais a geração $\mathrm{Z}$ irá guiar o modelo de consumo e produção vigente; e como a pandemia de Covid-19 pode ter acelerado esse processo.

\section{As formas de expressão de consumo da sociedade moderna e o papel do designer nesse contexto}

Ao falarmos da construção de uma sociedade moderna, é necessário voltar no tempo para compreender os fatores históricos que contribuíram para essa construção e, também, é preciso ter em mente que não existe um consenso - entre filósofos e sociólogos - de como entramos na modernidade (BAUMAN, 2003). Para chegar ao que se tem como sociedade no século XXI, ocorreram diversas mudanças no quadro político, socioeconômico e cultural que podem ser analisadas através de diferentes perspectivas. Assim, nesta etapa do artigo, foi realizado um breve estudo documental sobre 
acontecimentos históricos embasados na perspectiva de Weber (1976) e apoiados em conceitos de Bauman (2008) sobre consumismo e sociedade, para realizar a análise do tema em questão: as formas de expressão de consumo da sociedade moderna, bem como o papel do designer neste contexto.

Percebe-se, então, dois grandes eventos históricos que influenciaram a sociedade humana: a Revolução Francesa, que baseia-se na filosofia do iluminismo, a queda das monarquias e a ascensão de novas burguesias; e a Revolução industrial, onde a forma de produzir passa a ser muito mais rápida e em massa. Com o advento da revolução industrial e de novas tecnologias causadas pela perpetuação da energia elétrica, começou-se a falar de novas classes sociais. Para Weber (1976) estas classes sociais eram baseadas em poder aquisitivo, onde dividiam-se em classes de proprietários (fazendeiros, escravocratas), classes comerciais (banqueiros, donos de fábricas, mercantilistas) e a margem destas poderosas classes estavam os chamados desprivilegiados, divididos em 3 categorias: qualificados, semiqualificados e sem qualificação. Torna-se importante ressaltar esta visão liberal de Max Weber, pois dela foi semeada a ideia de pirâmide social em que a sociedade se apoia. Contextualizando, segundo Scalom e Salata (2012), a classe média nasce do crescimento das indústrias e dos mercados, onde surgiu um novo tipo de proprietário: administradores, gerentes, supervisores, técnicos, trabalhadores de escritório, vendedores, etc. Esta nova classe média intercala entre a alta e a baixa e gera um novo tipo de consumidor para o mercado. Com mais indústrias e mais consumidores, a disputa entre as marcas fica mais acirrada e o mercado percebe a necessidade da elaboração de publicidade e propaganda cada vez mais incisiva, afinal "quem aparece mais, vende mais" (THE RISE..., 2015). O consumo passa a ser característica intrínseca da sociedade ocidental moderna, fator que é reafirmado dentro do sistema econômico, tanto pela criação da necessidade de consumo, quanto mais posteriormente, através da implementação dos cartões de crédito que possibilitaram aos consumidores a oportunidade de ter o item desejado antes mesmo de ter o dinheiro para comprá-lo (BAUMAN, 2010).

É neste contexto que o design está inserido, enquanto agente difusor de uma sociedade de consumo e sua relação com a indústria. Mesmo que a ONU, na década de 1970, já apontasse a necessidade de se pensar em uma forma mais sustentável de se produzir e consumir, foi em 1990 que esta ideia se difundiu com mais força e o design sofreu duras críticas por desenvolverem produtos que incitavam o consumismo e o desperdício (MAGINI e BELUSSO, 2018). De acordo com Magini e Belusso (2018) o design é ligado ao modo de produção industrial capitalista, pois o seu desenvolvimento tem forte relação com a economia e a sociedade. Tendo em vista a relação do designer com a indústria e que este modelo de superprodução capitalista gera um enorme desequilíbrio no meio ambiente e na sociedade, começou-se a pensar em um desenvolvimento sustentável. Segundo Naime et al. (2012) pensar na fabricação de produtos sustentáveis, é pensar em seu ciclo de vida e que ao fim dela possa ter uma reutilização. Quando pensamos em reaproveitamento de um material e seu ciclo de vida, ponderamos sobre uma reciclagem que envolve um processo industrial ou transformação dele, mas isto ainda pode acarretar danos ao meio ambiente, além do que existem materiais que são ditos como "não recicláveis". Materiais não recicláveis são aqueles com mais de uma matéria prima, como o papel cartonado, por exemplo. Sobre isto o Instituto GEA (20--) explica:

“[...]embalagens cartonadas tipo longa vida, cujo material é formado por três tipos diferentes de matérias-primas (papel, alumínio e plástico). Sua reciclagem é possível, porém dificultada pela existência de poucas plantas industriais que atuam no reprocessamento e pelas condições impostas por essas empresas para sua coleta (exige-se que o material esteja limpo, prensado e em grande tonelagem)." (INSTITUTO GEA, 20--)

Neste contexto é importante que o designer compreenda o produto muito além da estética e funcionalidade, é preciso pensar de forma sustentável, elaborando produtos que impactem o mínimo ao meio ambiente (SILVA, Giorgio G. et. al, 2008). Portanto, refletir sobre a concepção de um produto, seu ciclo de vida e de como podemos estendê-lo e reutilizar sua matéria-prima, é de suma importância. 


\subsection{Impactos ambientais gerados pela cultura do consumo}

Segundo a ONU (2020), a população mundial começou a tomar consciência da necessidade de ações que garantissem a sustentabilidade dos recursos do planeta. Foi, então, convocada a Conferência das Nações Unidas sobre o Ambiente Humano, em Estocolmo (Suécia). Esse evento ocorreu no ano de 1972 e estabeleceu, em um manifesto ambiental, 19 princípios para inspirar a sociedade a preservar o meio ambiente. Sobre a preocupação na época, o manifesto alerta:

"Chegamos a um ponto na História em que devemos moldar nossas ações em todo o mundo, com maior atenção para as consequências ambientais. Através da ignorância ou da indiferença podemos causar danos maciços e irreversíveis ao meio ambiente, do qual nossa vida e bem-estar dependem. Por outro lado, através do maior conhecimento e de ações mais sábias, podemos conquistar uma vida melhor para nós e para a posteridade, com um meio ambiente em sintonia com as necessidades e esperanças humanas..." (ESTOCOLMO, 1972 apud ONU, 2020)

Dentro destas diretrizes, conforme ONU (2020), em 1987 foi lançado o Relatório Brundtland, denominado "Nosso Futuro Comum". Nele são abordadas ideias de que, para obter um desenvolvimento sustentável, é preciso também compreender nossa sociedade, de forma a direcionar investimentos e tecnologia em prol de um consumo e produção conscientes, proporcionando assim uma mudança institucional para o futuro das novas gerações. E que, ainda, precisamos pensar que a pobreza e a desigualdade estão ligadas às crises ecológicas: “[...]O desenvolvimento sustentável requer que as sociedades atendam às necessidades humanas tanto pelo aumento do potencial produtivo como pela garantia de oportunidades iguais para todos" (BRUNDTLAND, 1987 apud ONU, 2020). Inspirado no Relatório Brundtland foi realizada uma nova conferência em prol do meio ambiente e do desenvolvimento humano em 1992, no Rio de Janeiro, a "Cúpula da Terra". Assim adotaram a "Agenda 21" onde os governos mundiais se comprometeram com um desenvolvimento sustentável, a fim de se afastar daquele quadro de produção que tanto estava poluindo, quanto fortalecendo a desigualdade social. As áreas da agenda incluíam: proteger a atmosfera; combater o desmatamento, a perda de solo e a desertificação; prevenir a poluição da água e do ar; deter a destruição das populações de peixes; promover uma gestão segura dos resíduos tóxicos e ainda, abordar a pobreza e a dívida externa dos países em desenvolvimento (ONU, 2020). Estes eventos históricos foram apenas o "pontapé" inicial para que a sociedade começasse a agir em prol da sustentabilidade e a pensar em sua forma de produzir e consumir. Dentre tantas conferências realizadas pela Onu, podemos apontar a que ocorreu em 2015 em Nova Iorque, onde foram definidos novos objetivos para o desenvolvimento sustentável mundial, a ser alcançado até o ano de 2030 (ONU, 2020).

Ainda temos dez anos para buscar um desenvolvimento sustentável, porém, desde que essa conferência foi realizada, como está o nosso quadro mundial? Para consumir é preciso primeiro produzir. E já é sabido o quanto o modelo produtivo da nossa sociedade gerou a degradação do meio ambiente e, consequentemente, a escassez de nossos recursos naturais. Se por um lado, houve um crescimento econômico enorme a nível mundial, devido a globalização, por outro, nunca houve tanta miséria e degradação ambiental (ROSA, 2019). Não podemos separar produção e consumo na sociedade da desigualdade que este modelo econômico proporciona. Sobre isto a Global Footprint Network (apud ROSA, 2019), uma organização internacional de pesquisa responsável pelo cálculo anual do famoso "dia da sobrecarga da terra", aponta que a terra já está chegando ao seu limite. Para isso são levados em conta quatro fatores essenciais que resultam nesta sobrecarga, sendo eles: o quanto nós consumimos em nosso cotidiano; com que eficiência e frequência produtos são feitos; a densidade demográfica do planeta; e quanto o ecossistema é capaz de produzir (ROSA, 2019). Em seu levantamento sobre a sobrecarga que estamos proporcionando ao nosso meio ambiente, a organização Global Footprint Network (apud ROSA, 2019), ainda aponta que, atualmente, precisamos de mais de uma terra para aguentar tanto consumo, podemos exemplificar esta analogia com o gráfico (1) abaixo: 


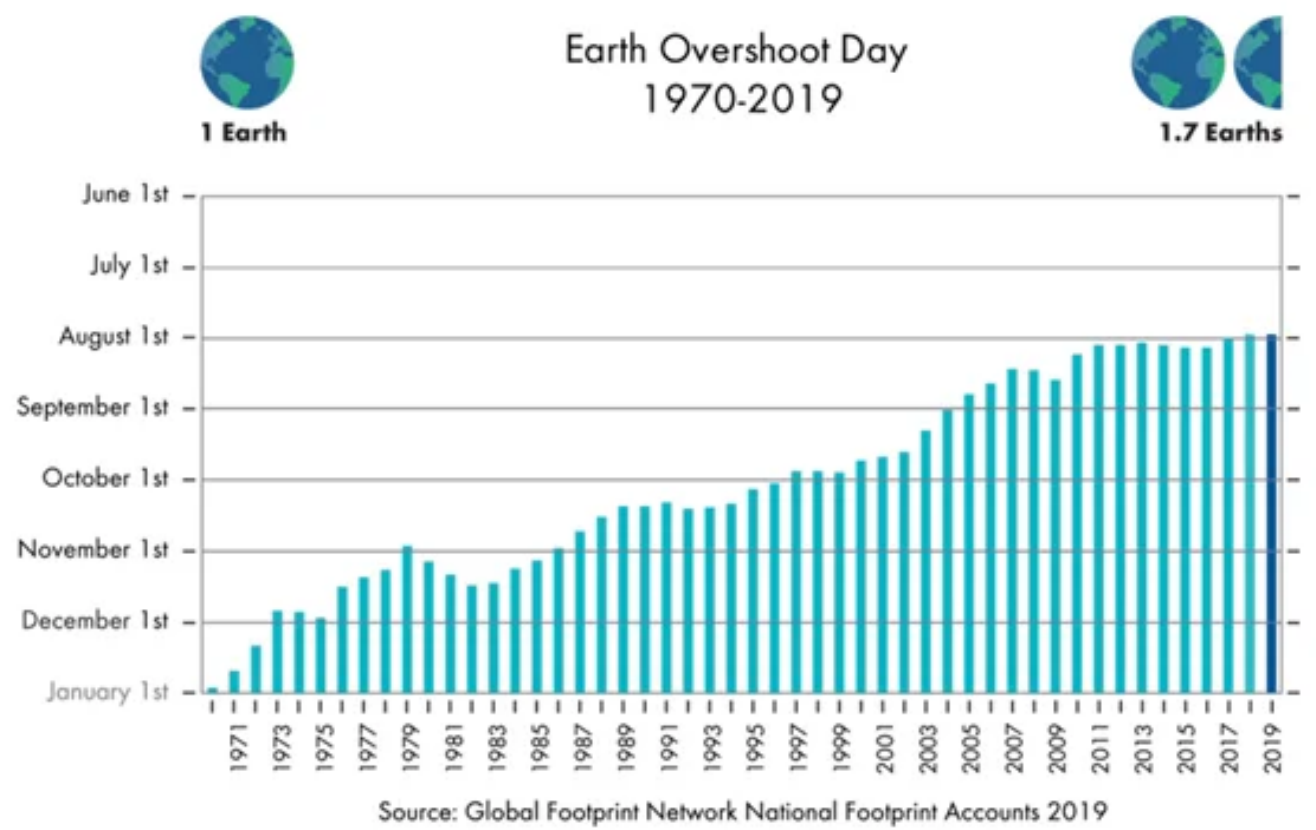

Gráfico 1 - Gráfico de sobrecarga da Terra. Fonte: Ciclovivo, 2020.

Torna-se cada vez mais importante que pensemos a forma como consumimos e produzimos. Naime et al. (2012) aponta que este comportamento de consumir exageradamente levou a indústria a sempre criar novos produtos, a fim de suprir a demanda da população. Gerando assim produtos de má qualidade, com vida curta, e que, por sua vez, eram descartados rapidamente. Estes fatores geram um grande acúmulo de resíduos sólidos que poluem o meio ambiente. Naime et al. (2012) salienta que “[...] existe ainda a percepção da escassez dos recursos naturais e das matérias primas que pode se tornar relevante, além da poluição e a emissão de gases em geral e gases de efeito estufa pela indústria". Por isso é dever da sociedade contemporânea pensar em novos padrões econômicos que visem um desenvolvimento sustentável. Uma das possibilidades mais viáveis para a população é o "Do it Yourself" que aliado ao design sustentável, pode trazer mudanças significativas no meio ambiente, começando de dentro de nossas casas.

\section{Percepções sobre o movimento DIY, a geração $Z$ e a pandemia de Covid-19}

$\mathrm{Na}$ sociedade globalizada, o uso da internet e novas tecnologias permite à geração $\mathrm{Z}$ maior relação com o mundo para expressar seu modo de pensar e agir. Isso recai em sua relação com formas de consumo e produção, onde buscam alternativas mais sustentáveis do que os modelos tradicionais (FRANCIS e HOEFEL, 2018). A ressignificação de produtos através de técnicas de upcycling e do Do It Yourself podem ser usadas como excelentes mecanismos dessa geração, já que essas técnicas possibilitam a criação de peças personalizadas, onde os zoomers - jovens da geração $\mathrm{Z}$ - podem expressar sua individualidade ao longo do processo.

O Movimento Do It Yourself (DIY ou "faça-você-mesmo" em tradução literal) pode ser descrito como "qualquer criação, modificação ou reparo de objetos sem a ajuda de profissionais pagos" (Kuznetsov; Paulos, 2010). Ele surge como resposta à crise financeira, também como um movimento contra o capitalismo e a superprodução industrial. Podemos pensar no DIY também como uma forma de produção sustentável mais acessível para a população. Dessa forma, podemos atribuir ao movimento, diversas facetas que podem ir desde criações de peças de roupas a auto prestação de serviços, geralmente realizados por terceiros. O DIY pode ser também associado a outros movimentos, como o upcycling e o maker, caracterizando-se como um movimento democrático e sustentável. Ele possibilita a criação de novos produtos a partir de materiais que podem ser encontrados na própria casa podendo se tornar uma fonte de renda para seus usuários (ROSA, 2018). Dessa forma, podemos abordar o DIY como uma alternativa que liga a sustentabilidade econômica, ambiental e social. 
O DIY tem suas origens na década de 1950 quando a sociedade passava por uma crise econômica pós-guerra, sendo necessário aprender a fabricar os próprios produtos, bem como fazer reparos caseiros, visto não haver dinheiro para pagar mão de obra qualificada (PRADO, 2011). Posteriormente, o DIY tomou uma forma mais expressiva entre as gerações seguintes, tornando-se uma maneira de protesto contra a cultura do consumismo. É possível observar essa atitude crítica na geração Z, que nasce entre 1995 e 2010, cresce em um mundo globalizado e toma consciência social quanto à forma irresponsável de consumo (FRANCIS e HOEFEL, 2018).

É interessante percebermos como a juventude, independente da geração, tem o potencial de questionar a época em que vive e sempre busca trazer mudanças. Um exemplo desse comportamento pode ser observado na experiência de vida da designer e ativista ambiental Vivienne Westwood, apresentado através do documentário Vivienne Westwood - Do it Yourself! (2011), que na década de setenta utilizava da estética punk e o $D I Y$ de forma transgressora, com críticas sociais, ressignificando peças de roupas já fabricadas pela indústria (VIVIENNE..., 2011). Vivienne Westwood aborda a importância de que a nova geração se preocupe com o meio ambiente e com a sua forma de consumir produtos (DEENY, 2018). Ao pensarmos na forma como a geração passada, a partir do exemplo de Westwood, preocupa-se com o meio ambiente e vê a necessidade de que a nova geração faça algo a respeito, podemos entender a importância da geração $Z$ para que tenhamos uma mudança significativa no quadro socioambiental em que vivemos.

Observar como a geração que já nasce envolta ao mundo virtual convive com o mundo tangível é uma tarefa fascinante. Mais atentos a questões ambientais e dispostos a buscar uma identidade única, a geração $Z$ une características que contribuem para a disseminação de novos modelos de consumo em diferentes esferas sociais. Segundo Francis e Hoefel (2018), os nascidos entre 1995 e 2010 fazem parte de uma "geração hiper cognitiva, muito confortável em coletar e fazer referências cruzadas de muitas fontes de informações e em integrar experiências virtuais e offline". Essas características tornam os zoomers capazes de assimilar diferentes realidades, compreendê-las e respeitá-las. Assim, observamos um novo grupo social formado por cidadãos ativos, empáticos e engajados a diferentes causas.

Trata-se de uma geração que valoriza muito a individualidade (CRITEO, 2018). Eles influenciam e também são influenciados - a fim de formar essa identidade única - e as redes sociais desempenham um importante papel nesse meio. Essa individualidade, contudo, abraça a individualidade do outro, o que para o Zoomer é fundamental na construção de um modelo social mais saudável. Para Bauman (2010), "reconhecimento social significa a aceitação dos outros, a confirmação de que o indivíduo optou por uma vida decente, que vale a pena e que merece todo o respeito das outras pessoas; o oposto do reconhecimento social significa a negação da dignidade, a humilhação". Assim, essa geração não tende ao julgamento do outro pela sua escolha de modo de vida e essa característica comportamental reflete em diferentes hábitos, como na forma de consumo, que acaba por se dar de maneira diferente das gerações passadas, por exemplo (FRANCIS e HOEFEL, 2018). Ademais, a conscientização sobre a sustentabilidade faz desse jovem um consumidor exigente, segundo Criteo (2018): eles valorizam marcas para além do nome, eles querem sentir que sua individualidade é assegurada e querem se identificar com os posicionamentos da empresa frente a suas causas. Assim, o consumo para os Zoomers tem um novo significado, diferente das gerações anteriores, o consumo transgride a fronteira da "posse" e ganha papel dentro da identidade, alterando o antigo viés "eu sou o que consumo" e se transformando em "eu sou como consumo". Dessa forma:

"A geração $\mathrm{Z}$ tem como uma de suas principais características a expressão da identidade individual. O consumo torna-se um meio para atingir essa singularidade muito diferente de gerações anteriores que compravam e usavam marcas para pertencer a um determinado grupo ou adquirir certo status. Liderados pela geração Z e os millennials, os consumidores estão, cada vez mais, buscando produtos personalizados que ressaltam sua individualidade [...] A expressão da identidade por meio das marcas significa ainda que as pessoas preferem consumir produtos ou serviços de empresas que defendam causas com as quais se identificam. " (FRANCIS e HOEFEL, 2018) 
O espargimento da internet possibilitou a disseminação mais rápida de informação e comunicação, fazendo com que a geração que já nasce envolta nesse ambiente virtual seja muito mais inclusiva, assim, para Francis e Hoefel (2018), "eles não fazem distinção entre amigos que fazem no mundo online ou offline". A evolução nos meios de comunicação possibilitou também que diversas culturas pudessem interagir em torno de seus interesses em comum, característica valorizada por essa geração (FRANCIS e HOEFEL, 2018). Esses interesses são também citados por Owen, Napoli e Shin (2018), que caracterizam a geração $\mathrm{Z}$ como uma geração de indivíduos muito diferentes, porém muito unidos por suas características partilhadas, onde "as diferenças não os assustam como poderiam ter assustado no passado" (OWEN. NAPOLI e SHIN, 2018). Segundo Francis e Hoefel, a palavra "comunidade" está mais atrelada aos interesses em comum para $66 \%$ desses jovens, do que para nível educacional e classes sociais, como ocorria em algumas gerações anteriores.

\subsection{A geração Z e o DIY}

Para Francis e Hoefel (2018), a facilidade de compartilhar e encontrar informações online também torna a geração Z bastante autodidata e, segundo o The Telegraphy (2019), os zoomers, apesar de mais novos, são melhores em realizar atividades como trocar lâmpadas, lubrificar fechaduras e reparar móveis que seus antecessores, os millennials.

As atividades DIY ganharam força também com a difusão das redes sociais, segundo Williams (2020), em pesquisa com diferentes faixas etárias tem-se que $78 \%$ dos entrevistados buscam informações online sobre os projetos, tendo YouTube e o Pinterest como principais fontes de referência (WILLIAMS, 2020). Ao analisarmos a rede social TikTok, com $41 \%$ dos seus usuários entre os $16 \mathrm{e}$ 24 anos (MEIO E MENSAGEM, 2019) verifica-se que a hashtag "DIY" já recebeu mais de 45 bilhões de visualizações (TIKTOK, 2020). A partir da busca pelo termo podem ser encontrados projetos como maquetes de casas, criações de vestidos de festa, cartões postais, pingentes de cera, capas para smartphones e, até mesmo, próteses dentárias (Imagem 1).

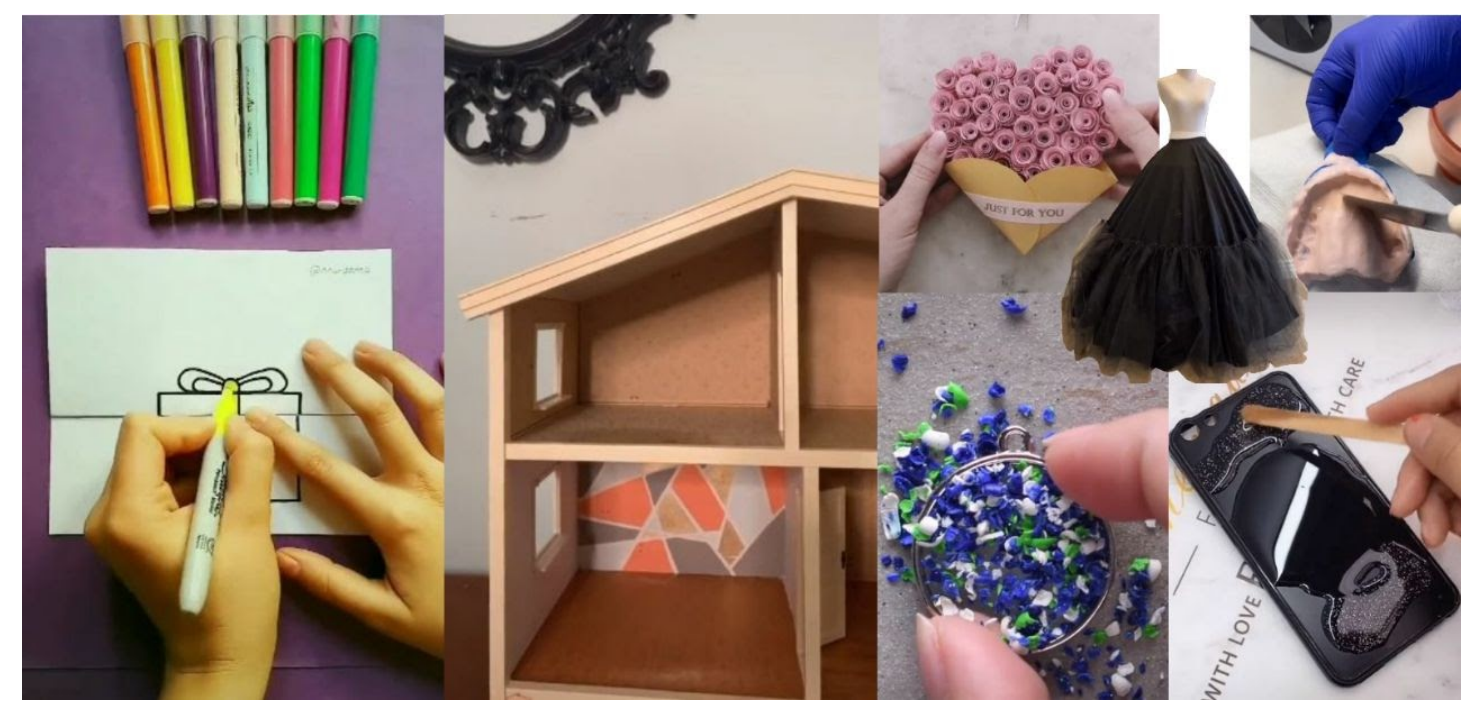

Imagem 1 - Moodboard criado a partir de printscreens dos vídeos disponibilizados no TikTok com a hashtag "DIY". Fonte: TikTok (2020).

Para além disso, vemos também que o $D I Y$ pode evoluir para uma forma rentável de produção, mesmo que o movimento surja de uma ideia de cooperação coletiva e não exploração do lucro (KUZNETSOV e PAULOS, 2010). As marcas oriundas da prática de DIY são também uma oportunidade para o jovem da geração $\mathrm{Z}$ expressar sua individualidade, tão valorizada, através da fabricação ou da compra desses itens.

Na moda, a preocupação com a sustentabilidade faz com que técnicas como o upcycling, que tenciona aumentar o ciclo de vida de produtos já existentes, tornem-se comuns (imagem 2). O interesse dessa geração em produtos personalizados é tamanho que, segundo Maguire (2020), eles são $90 \%$ dos 15 
milhões de registrados no Depop, uma plataforma global de revenda de itens, que fez com que essas iniciativas de customização, provindos do Do It Yourself, se tornassem um negócio para muitos dos seus usuários. Daniel Walters, criador da Sad Sac, loja de roupas personalizadas com hospedagem dentro da plataforma, aponta que "muitas pessoas [na geração Z] são apenas criativos que veem potencial nos itens de segunda mão e potencial em si mesmos como artistas" (WALTERS, 2020 apud MAGUIRE,2020). Outro exemplo do movimento DIY como fator impulsionador é a marca Resíduo, onde, segundo o site da empresa, os designers Jardel Schwaab e Ruan Escobar "cansados das inúmeras marcas de mochilas com estética padrão, decidiram desenvolver peças atemporais e exóticas para pessoas que, assim como eles, buscam por excentricidade visual" (RESIDUO, 20--).

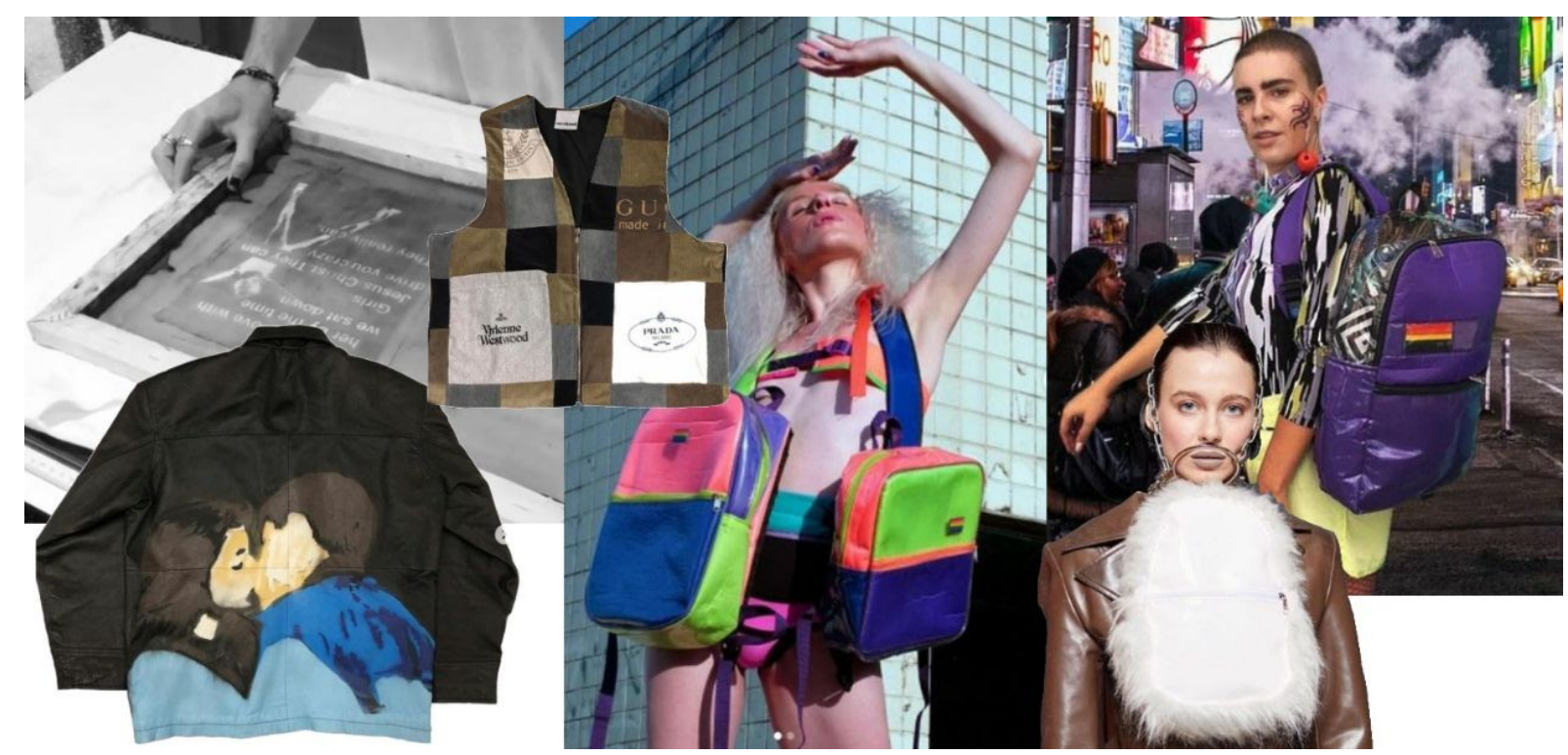

Imagem 2 - Moodboard das marcas citadas. Fonte: Perfis da marca no Instagram (2020)

Outra face do DIY que esta geração está mudando é a forma como as empresas utilizam o marketing. Uma geração marcada pelo FOMO ("fear of missing out" ou "medo de estar perdendo") anseia por estar sempre participando e se satisfaz em colaborar com as marcas na criação de produtos, serviços e dos conteúdos divulgados (CHARLESTON ORWIG, 20--). Um bom exemplo desse comportamento, que também acaba transpondo a barreira geracional, ocorreu no período de isolamento social, causado pela pandemia de Covid-19, quando diversas marcas tiveram que adaptar suas estratégias para a surpreendente nova realidade.

\section{O DIY durante a pandemia de Covid-19}

Segundo o Google Trends (2020), o crescimento nas pesquisas pelo termo "DIY" vinha tendo um crescimento constante entre os anos de 2010 e 2018, quando começa a estabilizar e decair. Contudo o pico do número de pesquisas - correspondente ao número 100 da linha de popularidade ao longo do tempo - ocorreu em abril de 2020, como mostra a gráfico 2, e coincide com o período em que grande parte da população mundial foi posta em isolamento social devido a pandemia de Covid-19. 


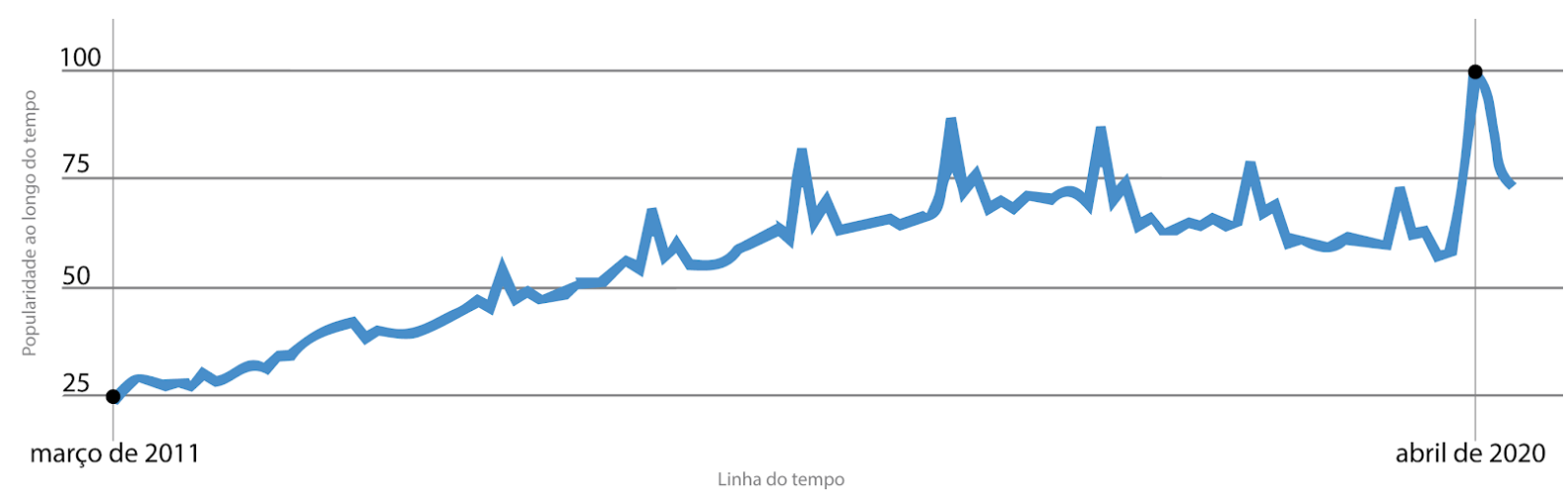

Gráfico 2 - Crescimento das pesquisas do termo "DIY" em todo mundo segundo o Google Trends (2020)

Dentro de suas casas por longos períodos e com receio da contaminação de itens vindos de fora, os hábitos de consumo mudaram. Reforçado pelo receio de uma iminente crise financeira, as pessoas passaram a dar prioridade a itens de primeira necessidade e comprados de forma online (SEBRAE, 2020). Segundo Press Association (2020), uma pesquisa realizada no Reino Unido diz que $38 \%$ das pessoas que estavam sob lockdown realizaram alguma atividade de DIY e $60 \%$ dos jovens de 18 a 34 anos se dizem estar envolvidos em algum projeto de faça você mesmo. Nesse cenário, a geração Z aparece novamente como destaque. Segundo Maguire (2020), 30\% dos "zoomers" estão adotando hábitos totalmente novos durante a pandemia, onde podemos citar a customização de roupas como um dos mais difundidos. Técnicas como o tie-die ganharam um grande espaço entre esses jovens pois são um "ponto de entrada fácil para a moda faça você mesmo [...] proliferada por tutoriais nas plataformas favoritas da Geração Z, YouTube e TikTok" (MAGUIRE, 2020).

Esses novos hábitos também começaram a ganhar incentivo vindo de um lugar bastante inesperado: as próprias marcas. A estratégia é também uma possibilidade de estreitar o relacionamento com o público, mostrar preocupação ambiental e passar uma imagem mais acolhedora, demandas bastante exigidas atualmente (CHITRAKORN, 2020). A exemplo disso, temos diversas propostas de desafios, engajadas por marcas como Alexander McQueen, Ganni e Shrimps, que incentivaram seus seguidores no Instagram a criarem looks com peças da marca de formas inusitadas, ensinaram técnicas de criação de playlists de músicas, entre outras atividades que podem ser associadas ao movimento $D I Y$. Outras facetas do DIY que chamaram bastante atenção nesse período foram as diversas iniciativas relacionadas a fotografia e vídeo. Ainda segundo Chitrakorn (2020) outra iniciativa provinda das marcas foi a parceria com celebridades e influencers que realizaram seus próprios ensaios fotográficos no período de isolamento social; outra iniciativa que podemos atribuir ao "faça você mesmo", uma vez que não há envolvimento de profissionais realizando o diretamente o serviço. Algumas destas iniciativas citadas podem ser visualizadas na imagem 3: 

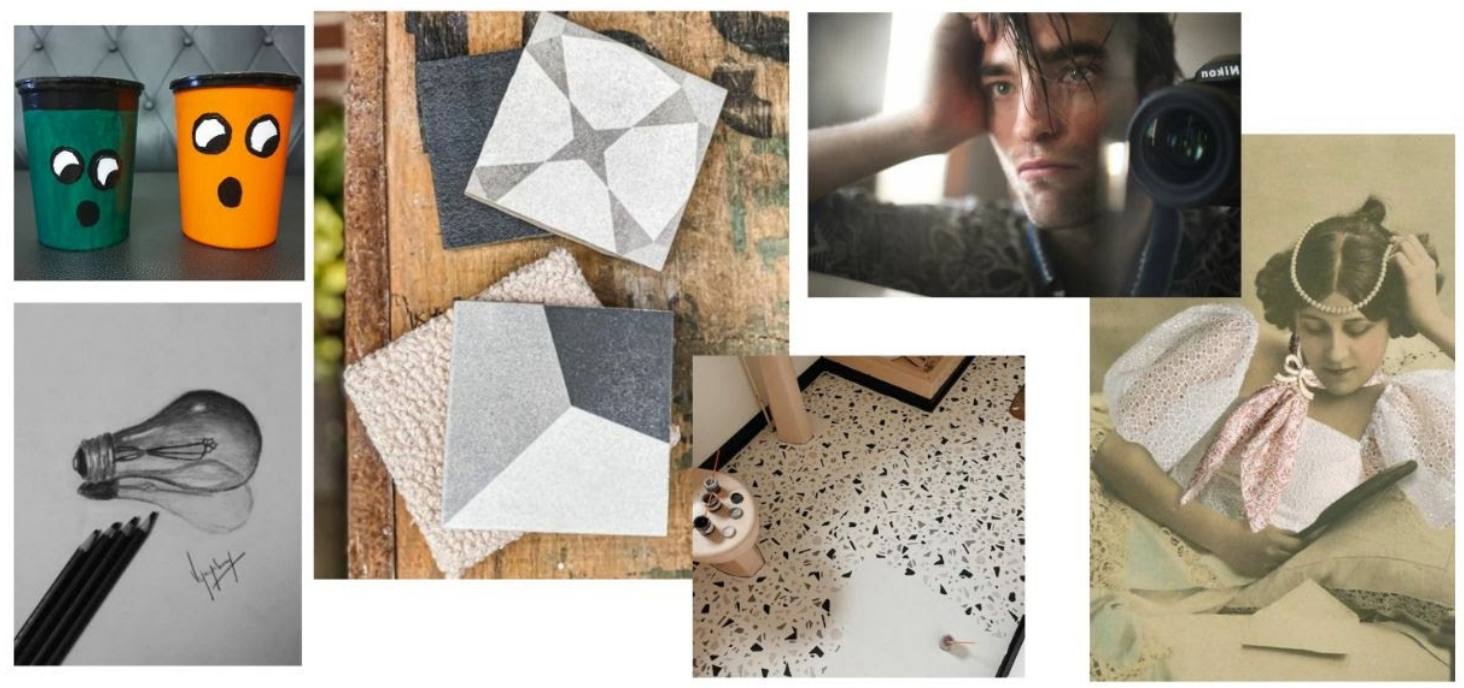

Imagem 3 - Quadro de iniciativas com viés DIY realizadas durante o período de isolamento social quarentena. Fonte: Instagram, 2020.

Independente da aresta de $D I Y$ explorada, é fato que o isolamento social proporcionou às pessoas um incentivo para buscarem novas maneiras de realizar ações do dia a dia, descobrir novos hobbies, auto afirmarem seu potencial e, até mesmo, encontrar novas fontes de renda.

\section{Considerações finais}

Ao fim da nossa exposição neste artigo, podemos perceber que a geração Z, por nascer envolta em um mundo digital com fácil acesso a informação, torna-se cada vez mais atenta a questões ambientais e a sociedade; criando assim um comportamento que influencia novos modelos de consumo. Os Zoomers assimilam diferentes realidades a ponto de compreendê-las e respeitá-las, o que os torna engajados em diversas causas. Esta influência de comportamento está amplamente ligada a evolução nas formas de comunicação, que possibilitaram a integração com diferentes culturas sem sair, necessariamente, da sua própria casa.

Se por um lado o ambiente virtual proporciona a integração com diferentes formas de pensar, por outro, ele auxilia na formação da identidade do jovem $Z$, que não recebe mais apenas informações provindas do seu ambiente físico e acaba por criar sua personalidade utilizando referências de fora de seu contexto social. Diferente das outras gerações, as influências desses jovens, muitas vezes, não podem ser encontradas no mesmo espaço que habitam e, por serem mais afeitos a diversidade, a miscigenação de referências é praticamente regra entre eles. Com a valorização das diferenças, a criação da identidade estética dos zoomers é mais híbrida e a adequação deles ao movimento DIY é uma excelente oportunidade para este jovem expressar sua singularidade, seja criando peças de roupas, decorando espaços ou testando técnicas. É interessante perceber que o projeto DIY parte, na génese do movimento, do próprio usuário final, sendo ele seu criador e possibilitando que o produto assuma a identidade do mesmo, definição que se encaixa sublimemente a essa característica de personalidade dos zommers.

Também, percebemos que o mundo moderno, do início do século XXI, é o resultado de uma produção e consumo irresponsável, levando a impactos ambientais, tanto no ecossistema como na saúde humana. Por isto, é importante que pensemos em uma nova forma de produzir e ressignificar o que já foi produzido e, nesta diretriz, podemos ressaltar a importância do Do it yourself, que propõe uma forma de aumentar o ciclo de vida do produto. $\mathrm{O}$ fato é: as características comportamentais demonstradas até agora pela geração $Z$ tem um papel forte dentro dessa lógica de transformação e, se manterem a mesma tendência comportamental, ela não tende a decepcionar. Podemos esperar também, que a crescente procura pela técnica de DIY, durante a pandemia de Covid-19, neste ano de 2020, possa trazer mudanças significativas na forma de produzir e consumir sustentavelmente em 
nossa sociedade. É interessante observar como essas mudanças já estavam sendo trazidas pela geração $\mathrm{Z}$ e como o isolamento social causado pela pandemia impulsionou essas novas formas de produção e consumo.

Desta forma, ao se compreender os motivos pelos quais as mudanças - ou a aceleração delas aconteceram é possível deduzir que esta geração $Z$ trará à tona ambições que eram timidamente vistas entre os jovens das gerações passadas. Neste contexto, é importante ressaltar o papel do design e de toda a sociedade em abraçar essas ambições, buscando um futuro comum onde o modelo de consumo seja mais justo, sustentável e saudável.

Test on the relationship between Zoomers and modern consumerism, their environmental impacts and the perception of sustainable from DIY

Abstract: Generation Z emerges in a society already characterized by the superfluous model of consumption and which reaps the fruits of this model through a generalized environmental crisis. However, more aware of these factors, both in terms of consumption and environmental sustainability, this generation embraces new ways of living in this society. Marked by the rise of the internet, the so-called "digital natives", are a generation that values individuality and respect, characteristics that fall on their consumption habits. They bring new points of view in the face of different social biases and, like other young people in their times, seek for improvements in this system. In this article, the consequences of these characteristics will be qualitatively analyzed through documentary research on the history of consumer habits in modern society and the DIY movement, which are gaining more and more space within this society.

Keywords: DIY; modern consumerism; generation Z; reframing

\section{Referências bibliográficas}

BAUMAN, Z. Modernidade líquida. Rio de Janeiro: Jorge Zahar, 2003.

BAUMAN, Z. A Vida para o consumo: a transformação das pessoas em mercadoria. Rio de Janeiro: Jorge Zahar, 2008.

BAUMAN, Z. Capitalismo parasitário e outros temas contemporâneos. Rio de Janeiro: Zahar, 2010.

CHARLESTON ORWIG. Move over Millennials: Gen $Z$ is changing the face of marketing. Charleston Orwig, 20--. Disponivel em: <https://charlestonorwig.com/move-over-millennials-gen-z-is-changingthe-face-of-marketing/>. Acesso em: 5 de agosto de 2020.

CHITRAKORN, K. How brands are connecting with customers in lockdown. Vogue, 2020. Disponivel em: <https://www.voguebusiness.com/companies/how-brands-are-connecting-with-customers-inlockdown>. Acesso em: 5 de agosto de 2020.

CRITEO. Como se expressa a geração Z: o que ela quer da moda. Criteo, 2018. Disponivel em: <https://www.criteo.com/br/insights/como-se-expressa-a-geracao-z-o-que-ela-quer-da-moda/>.

DEENY, G. Vivienne Westwood: as mudanças climáticas são mais importantes do que as roupas. Fashion Network, 2018. Disponivel em: <https://br.fashionnetwork.com/news/Vivienne-westwoodas-mudancas-climaticas-sao-mais-importantes-do-que-as-roupas,1000326.html>. Acesso em: 5 de agosto de 2020.

FRANCIS, T.; HOEFEL, F. 'True Gen': Generation Z and its implications for companies. McKinsey \& Company, Novembro 2018. Disponivel em: <https://www.mckinsey.com/industries/consumer- 
packaged-goods/our-insights/true-gen-generation-z-and-its-implications-for-companies>. Acesso em: 6 de julho de 2020.

GOOGLE TRENDS. DIY. Google Trends, 2020. Disponivel em:

<https://trends.google.com/trends/explore?date=all\&q=diy>. Acesso em: 5 de agosto de 2020 .

INSTITUTO GEA. O que pode ser reciclado? Instituto Gea, 20--. Disponivel em:

<https://www.institutogea.org.br/lixo/o-que-pode-ser-reciclado/>. Acesso em: 11 de agosto de 2020.

KUZNETSOV, S.; PAULOS, E. Rise of the Expert Amateur: DIY Projects, Communities, and Cultures. In: NORDIC CONFERENCE ON HUMAN-COMPUTER INTERACTION: EXTENDING BOUNDARIES, 6th, 2010, Reykjavik, Iceland. Proceedings... Reykjavik: 2010

MAGUIRE, L. With Gen Z under lockdown, DIY fashion takes off. Vogue, 2020. Disponivel em: $<$ https://www.voguebusiness.com/fashion/with-gen-z-under-lockdown-diy-fashion-takes-off>. Acesso em: 5 de agosto de 2020.

MANGINI, C. L.; BELUSSO, D. Design e Sustentabilidade: nexo histórico e categorias de abordagem. Revista Mundi, Curitiba, v. 3, n. 3, 2018. Disponivel em:

<https://www.researchgate.net/profile/Claudio_Mangini/publication/330425608_DESIGN_E_SUSTENT ABILIDADE_nexo_historico_e_categorias_de_abordagem_DESIGN_AND_SUSTAINABILITY_historical_ nexus_and_approach_categories/links/5c3f8ea892851c22a37a8b49/DESIGN-E-SUSTEN >. Acesso em: 2 de agosto de 2020.

MEIO E MENSAGEM. TikTok é a quarta maior rede social em número de usuários. Meio e Mensagem, 2019. Disponivel em:

<https://www.meioemensagem.com.br/home/midia/2019/11/21/tiktok-se-torna-a-quarta-maior-redesocial-em-numero-de-usuarios.html>. Acesso em: 8 de setembro de 2020.

NAIME ET AL. Do design ao ecodesign: pequena história, conceitos e princípios. Revista Eletrônica em Gestão, Educação e Tecnologia Ambiental, v. 7, n. 7, p. 1510-1519, 2012.

ONU. A ONU e o meio ambiente. ONU, 2020. Disponivel em: <https://nacoesunidas.org/acao/meioambiente/>. Acesso em: 11 de agosto de 2020.

OWEN, S.; NAPOLI, C.; SHIN, J. (2018). The Gen Z equation. WGSN.

PRADO, A. A volta da cultura do "faça você mesmo". Superinteressante, 2011. Disponivel em: <https://super.abril.com.br/cultura/a-volta-da-cultura-do-faca-voce-mesmo/>. Acesso em: 11 de agosto de 2020.

PRESS ASSOCIATION. Millennials and Gen $Z$ lead the way for DIY projects during lockdown. Evening Express, 2020. Disponivel em: <https://www.eveningexpress.co.uk/news/uk/millennials-and-gen-zlead-the-way-for-diy-projects-during-lockdown/>. Acesso em: 10 de agosto de 2020.

RESIDUO. Quem somos. Residuo, 20--. Disponivel em:

<https://www.residuobackpack.com.br/sobre>. Acesso em: 11 de agosto de 2020.

ROSA, M. Terra chega à sua sobrecarga de recursos naturais. Ciclo Vivo, 2019. Disponivel em: $<$ https://ciclovivo.com.br/planeta/meio-ambiente/terra-chega-a-sua-sobrecarga-de-recursos-naturais2019/>. Acesso em: 5 de agosto de 2020.

ROSA, P. C. D. Diretrizes para o desenvolvimento de empreendimentos, 2018. Disponivel em: <https://www.lume.ufrgs.br/bitstream/handle/10183/188271/001084997.pdf?sequence=1\&isAllowed $=y>$. Acesso em: 5 de agosto de 2020 .

SCALON, C.; SALATA, A. Uma nova classe média no Brasil da última década? O debate a partir da perspectiva sociológica. Soc. estado, Brasília, v. 27, n. 2, p. 387-407, 2012. Disponível em: <>. Acesso em: 08 de julho de 2020.

SEBRAE. Estudo mostra novo comportamento do consumidor diante da pandemia. Sebrae, 2020. Disponivel em: <https://m.sebrae.com.br/sites/PortalSebrae/artigos/estudo-mostra-novocomportamento-do-consumidor-diante-dapandemia,9388ad41eab21710VgnVCM1000004c00210aRCRD>. Acesso em: 10 de agosto de 2020. 
SILVA ET AL. O Design Gráfivo e o Desnvolvimento Sustentável. II Encontro de sustentabilidade em projeto do vale do Itajaí, 2008. Acesso em: 11 de agosto de 2020.

SZTALRYD, Letmiya. Direção: Vivienne Westwood: Do It Yourself. [S.I.]: [s.n.]. 2011. 1 Dolby Digital 2.0 (67 min), DVD, son., color.

THE RISE of Lowsumerism. Direção: André Alves, Lena Maciel, Rony Rodrigues e Sophie Secaf. Produção: K-Hole. Roteiro: André Alves, Lena Maciel, Rony Rodrigues e Sophie Secaf. Fotografia de João Felipe Veloso. Gravação de Fernanda Krumel, Lena Maciel e Lucas Moesch. [S. I.]: BOX1824, 2015. Disponível em: https://www.youtube.com/watch?v=jk5gLBIhJtA. Acesso em: 10 jul. 2020.

THE TELEGRAPH. Millennials are worse at DIY than younger generation $Z$, survey suggests. The Telegraph, 2019. Disponivel em: <https://www.telegraph.co.uk/news/2019/08/18/millennials-worsediy-younger-generation-z-survey-suggests/>.

TIKTOK. \#diy. TikTok, 2020. Disponivel em: <https://www.tiktok.com/tag/diy?lang=en>. Acesso em: 8 de setembro de 2020.

TRIBUNA, M. Pandemia adiou o Dia da Sobrecarga da Terra para Agosto. Público, 2020. Disponivel em: <https://www.publico.pt/2020/06/05/ciencia/noticia/pandemia-adiou-dia-terra-esgotariarecursos-naturais-2020-1919626>. Acesso em: 12 de agosto de 2020.

VIVIENNE Westwood - Do It Yourself!. Direção: Letmiya Sztalryd. Produção: Vivienne Westwood. Intérprete: Andreas Kronthaler, Vivienne Westwood. Roteiro: Jean-Marie Sztalryd, Letmiya Sztalryd. Fotografia de Sebastian Dewsberry. França: [s. n.], 2011. 1 Dolby Digital 2.0 (67 min), DVD, son., color.

WEBER, M. Classe, status, partido. In: VELHO, O.; PALMEIRA, M.; BERTELLI, A. R. Estrutura de classes e estratificação social. Rio de Janeiro: Zahar Editores, 1976. 